\section{New Technology Add-On Payment (NTAP) for Viz LVO: a win for stroke care}

\author{
Ameer E Hassan
}

\section{INTRODUCTION}

The Centers for Medicare and Medicaid Services (CMS) recently granted a New Technology Add-on Payment (NTAP) for Viz ContaCT (Viz LVO) by Viz.ai, Inc, an applied artificial intelligence healthcare company. ${ }^{1}$ This is the first time CMS has reimbursed an artificial intelligence (AI)based software using this designation. It applies to Viz.ai's acute ischemic stroke product, Viz LVO, officially known as Viz ContaCT, under which the ICD-10 Procedure Coding System (ICD-10-PCS) procedure code $4 \mathrm{~A} 03 \times 5 \mathrm{D}$ was established. Viz ContaCT is an AI-based system that creates a parallel alert system whenever it detects a large vessel occlusion (LVO) on a computed tomography angiogram. The images are viewable on a mobile application which combines HIPAA (Health Insurance Portability and Accountability Act)-compliant group messaging functionality with a mobile PACS Viewer. Users can view the images, make triage decisions, and communicate with other members of the care team through chat functionality.

Beyond the specific designation, this decision may have far-reaching implications for stroke care and for reimbursement of AI-enabled applications.

\section{What is NTAP?}

At a national level, reimbursement is how health care incentivizes helping patients. Medicare pays for a patient's hospital stay according to the Inpatient Prospective Payment System (IPPS) under a single bundled payment, which includes all costs. These payments are captured under the Medicare Severity Diagnosis-Related Group (MS-DRG) system. While the MS-DRG rates are updated annually, the payments are based on Medicare claims data accrued over a 2 to 3 year period. The result is that payments lag behind true costs, particularly for care using new and expensive technologies. ${ }^{2}$

Introduced in 2001, the CMS NTAP program was created by Congress to help close this gap and support timely access

Department of Neuroscience, Valley Baptist Medical Center, Harlingen, Texas, USA

Correspondence to Dr Ameer E Hassan, Department of Neurology, University of Texas Rio Grande Valley, Harlingen, Texas, USA; ameerehassan@gmail.com to innovative therapies for the Medicare population. For technologies accepted under this program, CMS provides an additional payment to hospitals above the standard MS-DRG payment amount. There is an application, review, and approval process for the NTAP program.

There are three criteria for NTAP:

- Newness-the technology must be novel, that is, $<3$ years old. Typically this excludes Food and Drug Administration (FDA) $510 \mathrm{k}$ clearances, as by definition, these are predicated on another technology

- Cost-the technology is not adequately covered under the existing MS-DRG

- Substantial clinical improvement-the technology must prove to CMS that it provides a substantial clinical advantage over other available technologies, typically in the form of improved patient outcomes.

NTAPs are granted based on evidence submitted with respect to specific products. Other AI companies can submit an application to CMS demonstrating they also meet the above criteria, for consideration in a future IPPS NTAP. ${ }^{3}$

\section{How the Viz.ai NTAP works}

In 2019, CMS revised its rules around reimbursement using the NTAP program, agreeing with concerns that capping the payment at the $50 \%$ rate may not adequately support healthcare innovations. In response, CMS increased payment to $65 \%$ of the lesser of (1) the cost of the new medical service or technology or (2) the amount by which the costs of the case exceed the standard DRG payment. ${ }^{4}$ For the Viz.ai NTAP code, the additional payment is capped at $\$ 1040$.

To qualify, a patient must be a Medicare patient with a suspected stroke, and the estimated cost must exceed the Medicare reimbursement. As the name suggests, the payment is added on to the DRG payment to the hospital for a qualifying patient, so only applies if the patient is admitted. In my institution, Medicare patients account for approximately $51 \%$ of our code strokes, and nationwide approximately $45 \%$ of these patients have an estimated cost greater than the DRG payment. ${ }^{5}$ For these patients, when the hospital uses Viz LVO the NTAP will help to defray costs with an additional payment, up to $\$ 1040$.

\section{Why this is a big deal for stroke}

Given the current revenue climate, a \$1040 reimbursement per patient may seem high. In approving NTAP for Viz LVO, CMS recognized the clinical benefit of Viz LVO in the management of patients admitted with stroke. Thrombectomy has been proven to be a highly effective treatment for acute ischemic stroke, and we know that patients do significantly better the sooner they are treated. ${ }^{6}$ It has been estimated that in each minute of an ongoing stroke, 1.9 million neurons, 14 billion synapses, and $12 \mathrm{~km}$ (7.5 miles) of myelinated fibers are destroyed and that the ischemic brain loses neurons at an hourly rate equivalent to 3.6 years of normal aging. ${ }^{78}$ Data from the Highly Effective Reperfusion Evaluated in Multiple Endovascular Stroke Trials (HERMES) collaborative suggests that every minute delay results in a loss of 4 days of disability-free life. ${ }^{9}$ Clearly, delays in stroke care result in significant negative outcomes both for patients and for the financial well-being of the healthcare system.

Cost-benefit analysis of thrombectomy yields similarly striking results: achieving expanded treatment in cerebral ischemia 3 (eTICI 3 ) over eTICI 2 b reperfusion resulted on average in 1.31 incremental quality-adjusted life-years (QALYs) as well as healthcare and societal cost savings of \$10327 and \$20224 per patient, respectively. An estimated \$21 million and \$36.8 million for the US healthcare system and society, respectively, could be saved by a $10 \%$ increase in the eTICI 2/3 reperfusion rate of all endovascular thrombectomy-treated patients with stroke. ${ }^{10}$

The median loss in net monetary benefit of thrombectomy per minute was calculated to be $\$ 1059$, and saving $10 \mathrm{~min}$ on average across the USA would save $\$ 249$ million annually. ${ }^{9}$ Implementation of Viz LVO has been demonstrated to save 66 min on average, ${ }^{11}$ suggesting a significant return on investment for CMS.

The intent of the NTAP program is to encourage early adoption of new and clinically effective technology. The reimbursement, however, may also help to avoid perverse incentives in the healthcare system, in which clinically appropriate transfers to comprehensive stroke centers may be discouraged by either the receiving or sending facilities, due to issues of avoiding the cost of sicker patients or 
retaining the reimbursement of funded patients. $^{12}$

We have made great progress in our ability to treat stroke and change lives. Evidence of health benefits, however, do not necessarily translate into evidence of financial feasibility, and healthcare systems may defer purchase of potentially life-saving and cost-saving products until the financial concerns have been alleviated. This decision represents a move by CMS to remove some of those barriers.

\section{Why this is a big deal for health care} CMS has previously proposed reimbursement for use of AI-enabled technologyspecifically automated retinal imaging-in its 2021 Medicare physician fee schedule proposed rule. ${ }^{13}$ This reimbursement model addresses diagnostic applications that perform functions analogous to those otherwise performed by physicians, but it is insufficient for novel uses, such as parallel processing and triage.

CMS grappled with several of these new concepts in its process of approving Viz ContaCT for NTAP. ${ }^{1}$ It had to determine how to define cost for an application with a subscription model-a common payment model for software, but not for physical tools. It had to understand how it should consider the "novelty" of technology given AI's capacity for learning and improvement. It also had to consider the value of technology to improve workflow, going beyond the traditional paradigms of straightforward diagnosis and treatment. Although healthcare AI tools and companies have been in the headlines over the past few years, healthcare has been slower to adopt AI-powered applications than other industries. Initial excitement over proofs-of-concept and early progress can quickly die without a viable financial model to support further development and deployment.

NTAP itself is unlikely to represent a comprehensive solution for large-scale AI market success, given the inherent limitations. It is a time-limited decision which is reviewed annually and expires after 3 years, at which point the cost of the technology may or may not be incorporated into the Medicare reimbursement calculation, and the cost-benefit considerations will change. The NTAP decision specifies a single product as qualifying for the additional payment, and CMS has to determine whether this applies to other products or not; to date, no other products have been deemed eligible by CMS. Additionally, the NTAP requirement of demonstrating novelty, high cost, and improved clinical outcome represents a barrier to acquire or even to attempt to acquire such a designation.

That said, the fact that CMS has begun to answer some of the questions of how AI-powered tools can be incorporated into reimbursement structures has illuminated a possible pathway to a realistic healthcare market for this technology.

\section{CONCLUSION/TAKEAWAYS}

In health care, doing the right thing for patients unfortunately is not enough. In order for new techniques, tools, and technology to be accepted and spread, they have to be incentivized. This is a landmark decision, as it marks the beginning of figuring out how we incentivize tools that target what is often the most challenging part of health care-the workflow issues that result from fragmented and unoptimized systems. It's a start to understanding how we might pay for advanced technology like AI, so we can accelerate adopting increasingly effective tools into our practices. More specifically, it's a win for stroke care, and the patients who will benefit from the treatment that we can provide, now more efficiently.

Time will tell, but we may look back and decide that this was the inflection point, the beginning of a new age in acceptance of this technology into the healthcare mainstream.

\section{Contributors AEH is the sole contributor to this} manuscript.

Funding The author has not declared a specific grant for this research from any funding agency in the public, commercial or not-for-profit sectors.

Competing interests The author received no financial support for the authorship of this article. Dr Hassan serves as a consultant for Medtronic, Microvention, Stryker, Penumbra, Cerenovus, Genentech, GE Healthcare, Scientia, Balt, and Viz.ai.

\section{Patient consent for publication Not required.}

Provenance and peer review Not commissioned; externally peer reviewed.

Data availability statement Data sharing not applicable as no datasets generated and/or analyzed for this study.$$
\text { (2) }
$$$$
\text { OPEN ACCESS }
$$

Open access This is an open access article distributed in accordance with the Creative Commons Attribution Non Commercial (CC BY-NC 4.0) license, which permits others to distribute, remix, adapt, build upon this work non-commercially, and license their derivative works on different terms, provided the original work is properly cited, appropriate credit is given, any changes made indicated, and the use is non-commercial. See: http:// creativecommons.org/licenses/by-nc/4.0/.

(c) Author(s) (or their employer(s)) 2021. Re-use permitted under CC BY-NC. No commercial re-use. See rights and permissions. Published by BMJ.

\section{Check for updates}

To cite Hassan AE. J Neurolntervent Surg 2021;13:406-408

Accepted 6 November 2020

Published Online First 24 November 2020

J Neurolntervent Surg 2021;13:406-408.

doi:10.1136/neurintsurg-2020-016897

ORCID iD

Ameer E Hassan http://orcid.org/0000-0002-71487616

\section{REFERENCES}

1 Medicare Program. Hospital inpatient prospective payment systems for acute care hospitals and the long-term care hospital prospective payment system and final policy changes and fiscal year 2021 rates; quality reporting and Medicare and Medicaid promoting Interoperability programs requirements for eligible hospitals and critical access hospitals. (federal register August 18, 2020, p.58625-58636). Available: https://www.federalregister.gov/documents/2020/09/ 18/2020-19637/medicare-program-hospital-inpatientprospective-payment-systems-for-acute-care-hospitalsand-the

2 Kane NM, Manoukian PD. The effect of the Medicare prospective payment system on the adoption of new technology. The case of cochlear implants. $N$ Engl J Med 1989;321:1378-83.

3 Medicare Program. Payments for new medical services and new technologies under acute care hospital inpatient prospective payment system (federal register 07 SEP 2001). Available: https://www.federalregister. gov/documents/2001/09/07/01-22475/medicareprogram-payments-for-new-medical-services-and-new technologies-under-the-acute-care

4 Medicare Program. Hospital inpatient prospective payment systems for acute care hospitals and the long-term care hospital prospective payment system and policy changes and fiscal year 2020 rates; quality reporting requirements for specific providers; Medicare and Medicaid promoting Interoperability programs requirements for eligible hospitals and critical access hospitals (federal register 16 AUG 2019. Available: https://www.federalregister.gov/documents/2019/08/ 16/2019-16762/medicare-program-hospital-inpatientprospective-payment-systems-for-acute-care-hospitalsand-the

5 Medpac. Hospital inpatient and outpatient services (March 2016 report). Available: http://www.medpac. gov/docs/default-source/reports/chapter-3-hospitalinpatient-and-outpatient-servicesmarch-2016-reportpdf?sfvrsn=0

6 Goyal M, Menon BK, van Zwam WH, et al. Endovascular thrombectomy after large-vessel ischaemic stroke: a meta-analysis of individual patient data from five randomised trials. Lancet 2016:387:1723-31.

7 Campbell BCV, Khatri P. Stroke. Lancet 2020;396:129-42.

8 Saver JL. Time is brain--quantified. Stroke 2006:37:263-6.

9 Kunz WG, Hunink MG, Almekhlafi MA, et al. Public health and cost consequences of time delays to thrombectomy for acute ischemic stroke. Neurology 2020:95:e2465-75.

10 Kunz WG, Almekhlafi MA, Menon BK, et al. Public health and cost benefits of successful reperfusion after thrombectomy for stroke. Stroke 2020;51:899-907.

11 Hassan AE, Ringheanu VM, Rabah RR, Preston L, et al. Early experience utilizing artificial intelligence shows significant reduction in transfer times and length of 
stay in a hub and spoke model. Interv Neuroradiol 2020;26:615-22.

12 Ali SF, Fonarow G, Liang L, et al. Rates, characteristics, and outcomes of patients transferred to specialized stroke centers for advanced care. Circ Cardiovasc Qual Outcomes 2018;11:e003359.

13 Department of Health and Human Services, Centers for Medicare \& Medicaid Services. 42 CFR Parts 410
414, 415, 423, 424, 425. (CMS-1734-P) Medicare Program; CY 2021 Payment Policies Under the Physician Fee Schedule and Other Changes to Part B Payment Policies; Medicare Shared Savings Program Requirements; Medicaid Promoting Interoperability Program Requirements for Eligible Professionals; Quality Payment Program; Coverage of Opioid Use Disorder Services Furnished by Opioid Treatment Programs; Medicare
Enrollment of Opioid Treatment Programs; Electronic Prescribing for Controlled Substances for a Covered Part $D$ Drug Under a Prescription Drug Plan or an MA-PD Plan: Payment for Office/Outpatient Evaluation and Management Services; Hospital IQR Program; Establish New Code Categories; and Medicare Diabetes Prevention Program (MDPP) Expanded Model Emergency Policy. Proposed rule, 2020. 